overall dynamics are strong enough to produce chaos, lead to situations in which conventional methods of data analysis fail to reveal the densitydependent mechanisms that are built into the model (and I cited an example drawn from experimental data $^{3}$ ). Other kinds of noise in parameters characterizing the behaviour of individuals create no such problems. Why some situations should result in difficulties in detecting density dependence, while others do not, remains the subject of investigation.

Mountford and Rothery's observation that no problems arise in their simple, phenomenological model is interesting. But it does not really address the main point in the paper by Hassell et al. ${ }^{3}$ or my News and Views article ${ }^{1}$.

Department of Zoology,

ROBERT M. MAY

University of Oxford,

South Parks Road,

Oxford OX1 3PS, UK

1. May, R. M. Nature 338, 16-17 (1989).

2. Bulmer, M. G. Biometrics 31, 901-911 (1975)

3. Hassell, M. P., Southwood, T.R.E. \& Reader, P. M. J. anim. Ecol. 56, 283-300 (1987)

\section{Is yeast TCP1 a chaperonin?}

SIR - G. North in his News and Views article $^{1}$ reports that the thermophilic bacterium Sulfolobus shibatae contains a gene, TF55, that is very similar in sequence to $T C P 1$ (ref. 2), suggestive of similar function. $T C P 1$ has a similar nucleotide sequence in mouse ${ }^{3}$, human ${ }^{3}$, hamster $^{2}$, Drosophila melanogaster ${ }^{4}$ and Saccharomyces cerevisiae ${ }^{5}$, making it a ubiquitous gene.

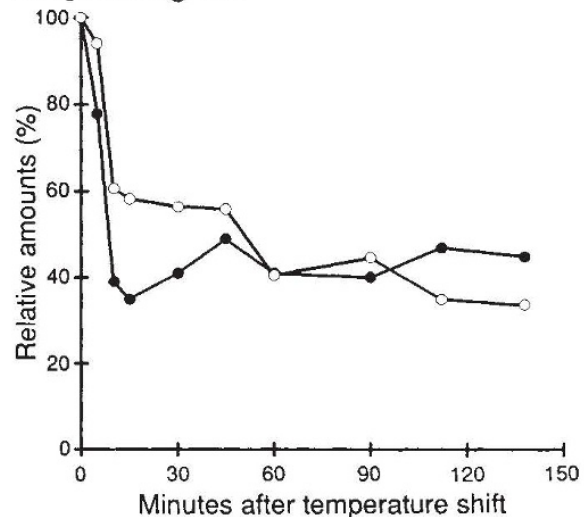

S. cerevisiae TCP1 and actin transcript levels of wild-type strain M10 (ref. 5) after heatshock. Relative transcript levels of TCP1 (solid circles) and, for comparison, actin (open circles). Cultures were shifted at time 0 from 24 to $38{ }^{\circ} \mathrm{C}$. The filter used to hybridize the TCP1 probe was rehybridized with an ACT1 probe. The absolute amounts of radiolabelled probe hybridized to specific bands was quantified on a Betascope Blot analyser (Betagen). One hundred per cent of counts for TCP1 and actin represent 1,810 and 6,487 counts, respectively.
The data concerning the heat-shock properties of TF55 in archaebacteria do not extend to its homologues in yeast and Drosophila. In yeast, the opposite is true. Transcription of TCP1 is repressed during heat stress as shown in the figure. Within $10 \mathrm{~min}$ after temperature shift from 24 to $38{ }^{\circ} \mathrm{C}$ the $T C P 1$ transcript level decreases by about $60 \%$, and remains low thereafter. The upstream noncoding sequence of yeast $T C P 1$ does not contain the consensus elements required for heat-induced transcription ${ }^{6}$. In agreement with the findings in yeast, the $D$. melanogaster homologue ${ }^{4}$, which maps to the chromosomal location $94 \mathrm{~B}$, is not associated with either the major or minor heat-shock puffs ${ }^{6}$ and thus is not in a chromosomal region known to encode a heat-inducible protein.

Another important characteristic of most chaperonins, that they are members of a multigene family, is not shared by the Drosophila or yeast TCP1 genes. The TCP1 genes in both organisms have no detectable sequence homologues and thus do not appear to be members of a family of related genes. If yeast and Drosophila TCP1 are indeed cytoplasmic chaperonins, they do not share two important attributes found to be present in most chaperonins. This would make TCP1 a remarkable chaperonin.

D. URSIC

Laboratories of Molecular Biology and Genetics,

University of Wisconsin,

1525 Lindin Drive,

Madison, Wisconsin 53706, USA

1. North, G. Nature 354, 434-435 (1991).

Trent, J. D. Nimmersgern, E., Wall, J. A. Hartl, F. -U. \& Horwich, S. L. Nature 354, 490-493 (1991).

3. Willison, K. R., Dudley, K. \& Potter, J. Cell 44, 727-738 (1986).

4. Ursic, D. \& Ganetzky, B. Gene 68, 267-274 (1.988) 5. Ursic, D. \& Culbertson, M. R. Molec. cell. Biol. 11, 2629-2640 (1991)

6. Westwood, J. T., Clos, J. \& Wu, C. Nature 353, 822-827 (1991).

\section{Crystallization by centrifugation}

SIR - The Scientific Correspondence by J. E. Pitts ${ }^{1}$ about the crystallization of a protein by centrifugation is not unprecedented. First beef liver catalase and later fungal (Penicillium vitale) catalase were crystallized by ultracentrifugation and reported in the Soviet journal

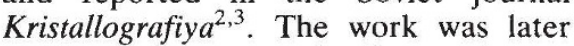
published in English in Soviet Physics, Crystallography ${ }^{4,5}$. V. Barynin presented this work at the FEBS advanced lecture course dedicated to the crystal growth of biological macromolecules (Bischenberg, Alsace, 19-25 July, 1987) $)^{6}$.

The Russian authors mentioned that the first virus coat protein was crystal- lized in an ultracentrifuge as early as $1936^{7}$. Ironically, a model of the threedimensional structure of $P$. vitale catalase, determined using the crystals grown by ultracentrifugation ${ }^{8}$, was built in the early 1980 s on the graphics system at Birkbeck College, London.

Cele Abad-Zapatero

Protein Crystallography Laboratory,

Abbott Laboratories,

Abbott Park,

IIlinois 60064, USA

PITTS REPLIES - Abad-Zapatero correctly refers to the production of catalase and tobacco mosaic virus (TMV) protein crystals in an ultracentrifuge ${ }^{7.8}$. In my Scientific Correspondence I alluded to this effect when I indicated that "high $g$-force" had been used successfully to approach the problem of crystallization. But apart from being crystallized while rotating in a centrifuge, the two methodologies are fundamentally distinct. The catalase crystals were grown at $26,000 \mathrm{~g}$ in a high-speed ultracentrifuge over 180 hours ( $71 / 2$ days) in the presence of a precipitant 2-methyl-2,4-pentanediol (MPD), while the large particle size TMV crystals are produced at $40,000 g^{7.8}$.

The crystals of the aspartic proteinase from Trichoderma reesei are grown rapidly ( $2 \frac{1}{2}$ hours), at low speed and ionic strength, during rapid concentration through an ultrafiltration membrane at quite low $(3,000 \mathrm{~g})$ centrifugal force. The nearest comparable method reported in the literature would be that of concentration dialysis 9 . The concentration process to produce protein crystals being achieved either by pressure dialysis under nitrogen ${ }^{10}$ or by vacuum dialysis through conical collodian membranes ${ }^{11,12}$. The commercial availability of centricon concentrators (Amicon) and of suitable slow-speed centrifuges with a fixed-angle rotor in most laboratories involved in protein purification should mean that the technique could be used more generally.

JIM E. PITTS

Department of Crystallography,

Birkbeck College,

University of London,

Malet Street, London WC1E 7HX, UK

1. Pitts, J. E. Nature 355, 117 (1992).

2. Karpukhina, S. Ya Barynin V. V. \& Lobanova, G. M. Kristallografiya 20,680-681 (1975)

3. Barynin, V. V. \& Melik-Adamyan, W. R. Kristallografiya 27 981-987 (1982)

4. Karpukhina, S. Ya., Barynin. V. V. \& Lobanova, G. M. Soviet Physics, Crystallography 20, 417 (1975)

5. Barynin. V. V. \& Melik-Adamyan. W. R. Soviet Physics, Crystallography 27, 588 (1982).

6 Barynin. V. V. FEBS AdV. Lect. Course Crystal Growth of Biological Macromolecules 70 (1987)

. Wyckoff, R. W. G. \& Corey, R. B. Science 84, 513-514 (1936).

8. Vainshtein, B. K. et al. J. molec. Biol. 188. 49-55 (1986).

9. McPherson. A. Preparation and Analysis of Protein Crys tals (Wiley, New York, 1982).

10. Satow, Y. et al. J. molec. Biol. 75, 745-746 (1973)

11. Kauffman, D. L. et al. Archs biochem. Biophys. 137 325-339 (1970)

12. Richardson, D. C., Bier, J. C. \& Richardson, J. S. J. biol Chem. 247, 6368-6369 (1972). 